\title{
Impact of Covid-19 Disease and National Lockdown on Outcomes of Emergency Surgery. Results From A Retrospective Comparative Cohort Study In A Tertiary Referral Teaching Hospital
}

Francesco Antonio Ciarleglio ( $\square$ francesco.ciarleglio@apss.tn.it )

APSS https://orcid.org/0000-0002-1489-1954

Marta Rigoni

University of Trento: Universita degli Studi di Trento

Liliana Mereu

Santa Chiara Hospital-Trento (Italy)

Tommaso Cai

Santa Chiara Hospital-Trento(Italy)

Alessandro Carrara

Santa Chiara Hospital-Trento(Italy)

Gianni Malossini

Santa Chiara Hospital-Trento (Italy)

Saverio Tateo

Santa Chiara Hospital-Trento (Italy)

Giuseppe Tirone

Santa Chiara Hospital-Trento (Italy)

Truls E Bjerklund Johansen

Oslo University Hospital: Oslo Universitetssykehus

Pier Paolo Benetollo

Trento Provincial Authority for Health Services: Provincia autonoma di Trento Azienda Provinciale per i Servizi Sanitari

\section{Antonio Ferro}

Trento Provincial Authority for Health Services: Provincia autonoma di Trento Azienda Provinciale per i Servizi Sanitari

Giovanni Maria Guarrera

Trento Provincial Authority for Health Services: Provincia autonoma di Trento Azienda Provinciale per i Servizi Sanitari

\section{Mario Grattarola}

Trento Provincial Authority for Health Services: Provincia autonoma di Trento Azienda Provinciale per i Servizi Sanitari 


\section{Giandomenico Nollo}

University of Trento: Universita degli Studi di Trento

Alberto Brolese

Santa Chiara Hospital-Trento (Italy)

\section{Research article}

Keywords: COVID-19, demographic, anamnestic, surgical

Posted Date: February 19th, 2021

DOl: https://doi.org/10.21203/rs.3.rs-234624/v1

License: (c) (1) This work is licensed under a Creative Commons Attribution 4.0 International License. Read Full License

Version of Record: A version of this preprint was published at World Journal of Emergency Surgery on July 13th, 2021. See the published version at https://doi.org/10.1186/s13017-021-00382-z. 


\section{Abstract}

BACKGROUND: The aim of this retrospective comparative study was to assess the impact of the COVID19 related disease on emergency surgery, comparing clinical main outcomes in the period March -May 2019 (Group 1) with the same period in Covid-19 Italian lockdown (March-May 2020, Group 2).

METHODS: A comparison (Group 1 versus 2) was performed between the demographic, anamnestic, surgical, clinical and management features.

RESULTS: 246 patients were included, 137 in Group 1 and 109 in Group 2 ( $p=0.03$ ). No significant differences in peri-operative characteristics were registered. A declared delay in access to hospital and SARS-CoV-2 preoperatively infection rates were $15.5 \%$ and $5.8 \%$ respectively in Group 2 . The overall morbidity $(\mathrm{OR}=2.22,95 \% \mathrm{Cl}=1.08-4.55, \mathrm{p}=0.03)$ and 30-day mortality $(\mathrm{OR}=1.34,95 \% \mathrm{Cl}=0.33-5.50,=0.68)$ increased significantly in Group 2. Delayed access cohort demonstrated a close correlation with increased morbidity $(\mathrm{OR}=3.19,95 \% \mathrm{Cl}=0.89-11.44, \mathrm{p}=0.07)$, blood transfusion $(\mathrm{OR}=5.13,95 \% \mathrm{Cl}=1.05$ $25.15, p=0.04)$ and a 30-day mortality risk $(O R=8.00,95 \% C l=1.01-63.23, p=0.05)$. Positive SARS-CoV-2 patients had higher risk of blood transfusion ( $20 \%$ vs $7.8 \%, p=0.37)$, ICU admissions ( $20 \%$ vs $2.6 \%, p=$ 0.17 ) and median LOS (9 days vs 4 days, $p=0.11$ ).

CONCLUSIONS: This article provides enhanced understanding of the effects of the COVID-19 pandemic on patients access to emergency surgical care. Our findings suggest that COVID-19 changed the quality of surgical care with poorer prognosis and higher morbidity rates. A delayed Emergency Department access and a "filter effect" induced by a COVID-fear in the population resulted in only the most severe cases reaching the Emergency Department in time.

\section{Introduction}

The SARS-CoV-2 virus infections and the related clinical signs of disease started in Wuhan, Hubei, China in the last days of 2019 and soon spread rapidly all around the world (1). On March 11, 2020, the World Health Organization (WHO) declared the infection to be a pandemic disease (2). COVID-19 became a public health crisis that has profoundly modified medical and surgical patient management. The Italian Government imposed a lockdown with significant restrictions on human contact, travel and business operations from March 10, 2020 onwards. During the period March-May 2020, Italy was the third most affected country after USA and Spain with 204,576 confirmed disease cases and 26,049 deaths (3). The Italian Health Care System 's response to COVID-19 and the related challenges have caused important changes in hospital activities. The vast number of COVID-19 patients requiring hospitalization and critical care exceeded the capacity of Italian hospitals. The most significant consequence was the stop of elective non-oncological surgical procedures and the switch from non-COVID-19 pathways to COVID-19 pathways according to international guidelines for all patients admitted to hospitals (4). Emergency Department (ED) and urgent surgical protocols were modified in all health regions with a subsequent complete redistribution and reorganization of activities and services. Our hospital is a regional hub for 
emergency surgery. During the first COVID-19 phase all peripheral hospitals were changed into Covid hospitals within short and a much higher number of emergency surgical procedures had to be performed in the regional hub with a potential unfavourable and unpredictable patients'outcome.

The aim of this retrospective comparative study was to assess the clinical impact of the COVID-19 related disease and restrictive healthcare measures applied in Italy on emergency surgery in our tertiary referral teaching hospital, by comparing clinical and management outcomes between the Covid-19 Italian lockdown period (March-May 2020) and the same period (March-May) of the previous year 2019.

\section{Materials And Methods}

\section{Patients setting and study schedule}

This study was planned as a retrospective cohort study comparing two separate groups of consecutive patients undergoing emergency surgical procedures in a tertiary referral teaching regional hospital before (March-May 2019, Group 1) and during the COVID-19 pandemic (March-May 2020, Group 2). Patients > 18 years of age admitted to the ED of the regional hub hospital for emergency operations in general surgery, gynecologic or urologic department were enrolled retrospectively. Exclusion criteria were age $<18$ years, incomplete follow-up data, re-operations after elective surgery, outpatient clinical visits in the recent 7 days, patients on waiting list and day hospital admissions. Emergency surgery was defined as any emergency or urgent procedures done by surgeons in an operative room under general anesthesia. Any emergency or urgent indication were eligible for inclusion which was done according to the STROBE statement (5).

\section{Variables and outcome}

Demographic, anamnestic, surgical, clinical and management characteristics were registered. The following scales, scores and parameters were registered at the time of admission to the ED: Numeric Rating Scale (NRS) for pain (6), National Early Warning Score (NEWS) (7), Charlson Comorbidity index score (CCI) (8), declared delayed access $>48$ hours, patients' diagnosis, presence/absence of sepsis criteria at admission (9), American Society of Anesthesiologists (ASA) score, SARS-CoV-2 swab test (only for Group 2). Surgical approach was classified as open, laparoscopic and endoscopic procedures (operative cystoscopy, hysteroscopy and vaginal approach). The main outcomes were intra-operative complications, Intensive Care Unit (ICU) admission, Diagnosis Related Groups (DRG) score, length of hospital stay (LOS), discharge pathway, post-operative complications according to Clavien-Dindo morbidity classification (10), intra/post-operative blood transfusion rate, in-hospital mortality and 30-day mortality. In-hospital mortality was defined as death during the same hospital stay and 30-day mortality was defined as death within 30 days after surgery. DRG score is a system for remuneration of hospitals based on the classification of the Diagnosis Related Groups (11). It is a system for measuring and enhancing hospital admissions for acute illnesses, representative and specific of the Italian reality. The system also provides tools for its continuous maintenance, with the aim of contributing to the improvement of hospital governance, allocation of resources, appropriateness and quality of care. 
Clinical data were collected by reviewing all electronic medical charts and, if needed, by reviewing medical ward charts and/or by calling the patients.

Data collection was performed by authors FAC, LM, AC, TC and statistical analysis was performed by MR.

The study was approved by the local institutional Ethical Committee and data acquisition and storage were compliant with guidelines of the institutional review board. The study was conducted in line with the Good Clinical Practice guidelines and the ethical principles according to the Declaration of Helsinki. All anamnestic, clinical or laboratory data containing sensitive information about patients were de-identified in order to ensure analysis of anonymous data only.

\section{Statistical analyses}

The descriptive variables were expressed by mean \pm standard deviation (SD) in case of normal distribution or by median and first and third quartiles (q1, q3, respectively) in case of non-normal distribution. The normality of the variables was tested with the Shapiro-Wilk test. The dichotomous variables or scores were expressed as frequencies and occurrence percentages. Characteristics of patient populations were compared with the most appropriate test according to the nature and normality of the data (Chi-squared test, Fisher exact test, Student t-test or U-Mann Whitney test when appropriate).

We performed univariate and multivariate logistic regression models to evaluate the real impact of COVID 19 on patients' outcomes. When appropriate, multivariate models were performed adjusting for ASA score, age, $\mathrm{CCl}$ at admission, and NEWS at admission. When logistic regression was not feasible, we reported numbers, percentages, $p$-value from Fisher exact test or median (q1-q3) and p-value from the UMann Whitney test.

Two subgroup analyses were performed for Group 2 (2020 patients). The first subgroup analysis evaluated the outcomes according to the patients' declared delayed admission, the second one, aimed to assess the impact of SARS-Cov-2 positivity on patients' outcomes versus to SARS-Cov-2 negative patients.

A p-value $<0.05$ was set for statistical significance. Statistical analyses were performed using the Stata software, StataCorp, 4905 Lakeway Drive, College Station, Texas 77845 USA.

\section{Results}

A total of 246 patients who received emergency/urgent surgery were included, with 137 operations performed during March-May 2019 (Group 1) and 109 during March-May 2020 (Group 2) (COVID 19 pandemic).

\section{Patients' characteristics, diagnoses and clinical management}


No significant peri-operative characteristics differences were registered in the two groups in terms of age, gender, NRS, NEWS, CCl, ASA score, presence/absence of sepsis criteria, surgical approach, ICU admission. On the other hand, the transfer from outside to hospital showed an increasing in ambulance use ( $16.8 \%$ vs $51.4 \%$ in Group 1 and 2 respectively, $p=0.03)$ with a consequently reduction of personal vehicle (Group $181.0 \%$ vs Group2 $46.8 \%, p=0.03$ ). Moreover, a declared delayed access to hospital was registered in $0 \%$ in Group 1 and in 16 subjects in Group $2(15.5 \%)(p<0.01)$. SARS-CoV-2 infection (tested only in Group 2) was diagnosed preoperatively in 5 cases of $86(5.8 \%)$ patients with nasopharyngeal swab. A statistically significant difference in overall population size was discovered (Group 1, $n=137$; Group 2, $n=109 ; p=0.03$ ) (Tables 1 and 2).

Table 1

Type of admission diagnoses

\begin{tabular}{|llll|}
\hline Diagnosis & Group 1 & Group 2 & p-value \\
& $\mathbf{2 0 1 9}$ & $\mathbf{2 0 2 0}$ & \\
& $\mathrm{n}(\%)$ & $\mathrm{n}(\%)$ & \\
\hline Overall Population & $\mathbf{1 3 7}$ & $\mathbf{1 0 9}$ & $\mathbf{0 . 0 3}$ \\
\hline Trauma & $4(2.9)$ & $4(3.7)$ & 0.73 \\
\hline Gastrointestinal perforation & $8(5.8)$ & $5(4.6)$ & 0.78 \\
\hline Bowel Obstruction & $12(8.8)$ & $20(18.3)$ & 0.03 \\
\hline Hernia & $5(3.6)$ & $4(3.7)$ & 1.00 \\
\hline Acute Appendicitis & $16(11.7)$ & $21(19.3)$ & 0.11 \\
\hline Acute Cholecystitis & $8(5.8)$ & $2(1.8)$ & 0.19 \\
\hline Bowel Ischemia & $1(0.7)$ & $0(0.0)$ & 1.00 \\
\hline Testicular Torsion & $2(1.5)$ & $0(0.0)$ & 0.50 \\
\hline Urinary Tract Bleeding & $9(6.6)$ & $2(1.8)$ & 0.12 \\
\hline Urinary Tract Obstruction & $39(28.5)$ & $23(21.1)$ & 0.24 \\
\hline Extrauterine Pregnancy & $3(2.2)$ & $7(6.4)$ & 0.11 \\
\hline Pelvic Inflammatory Disease (PID) & $3(2.2)$ & $5(4.6)$ & 0.47 \\
\hline Genital Bleeding & $2(1.5)$ & $2(1.8)$ & 1.00 \\
\hline Miscarriage & $4(2.9)$ & $6(5.5)$ & 0.34 \\
\hline Ovarian Benign Disease & $2(1.5)$ & $3(2.7)$ & 0.66 \\
\hline Other Relevant Surgical Pathology & $19(13.9)$ & $5(4.6)$ & 0.02 \\
\hline
\end{tabular}


Table 2

Patients' characteristics at admission.

\begin{tabular}{|c|c|c|c|}
\hline \multirow[t]{4}{*}{ Characteristics } & Group 1 & Group 2 & \multirow[t]{4}{*}{ p-value } \\
\hline & 2019 & 2020 & \\
\hline & (137 Pts) & (109 Pts) & \\
\hline & $\mathrm{n}(\%)$ & n (\%) & \\
\hline Age years, median (q1-q3) & $53(33-70)$ & $48(32-70)$ & 0.41 \\
\hline \multicolumn{4}{|l|}{ Gender, n (\%) } \\
\hline Female & $42(30.7)$ & $40(36.7)$ & \multirow[t]{2}{*}{0.32} \\
\hline Male & $95(69.3)$ & $69(63.3)$ & \\
\hline \multicolumn{4}{|l|}{ Pre-Hospital Transfer, n (\%) } \\
\hline Personal & $111(81.0)$ & $51(46.8)$ & \multirow[t]{3}{*}{$<0.01$} \\
\hline Ambulance & $23(16.8)$ & $56(51.4)$ & \\
\hline Helicopter rescue & $3(2.2)$ & $2(1.8)$ & \\
\hline \multicolumn{4}{|l|}{ NRS median (q1-q3) } \\
\hline$\leq 3, \mathrm{n}(\%)$ & $50(37.3)$ & $40(36.7)$ & \multirow[t]{3}{*}{0.98} \\
\hline $4-6, \mathrm{n}(\%)$ & $34(25.4)$ & $29(26.6)$ & \\
\hline$\geq 7, \mathrm{n}(\%)$ & $50(37.3)$ & $40(36.7)$ & \\
\hline \multicolumn{4}{|l|}{ NEWS at admission, median (q1-q3) } \\
\hline $0-4, n(\%)$ & $101(80.8)$ & $86(78.90)$ & \multirow[t]{3}{*}{0.39} \\
\hline $5-6, n(\%)$ & $10(8.0)$ & $14(12.8)$ & \\
\hline$\geq 7, \mathrm{n}(\%)$ & $14(11.2)$ & $9(8.3)$ & \\
\hline CCl, median (q1-q3) & $2(0-5)$ & $1(0-5)$ & 0.99 \\
\hline Declared Delayed access > 48h, n (\%) & $0(0.0)$ & $16(15.5)$ & $<0.01$ \\
\hline Sepsi criteria, n (\%) & $42(31.3)$ & $31(28.7)$ & 0.66 \\
\hline ASA score, median (q1-q3) & $2(1-3)$ & $2(1-3)$ & 0.35 \\
\hline \multicolumn{4}{|l|}{ ASA score, n (\%) } \\
\hline ASA 1 & $49(38.3)$ & $29(29.6)$ & \multirow[t]{2}{*}{0.36} \\
\hline ASA 2 & $42(32.8)$ & $35(35.7)$ & \\
\hline
\end{tabular}




\begin{tabular}{|llll|}
\hline Characteristics & Group 1 & Group 2 & p-value \\
& 2019 & 2020 \\
& $(137$ Pts) & $(109$ Pts) \\
& $\mathbf{n}(\%)$ & $\mathbf{n}(\%)$ \\
\hline ASA 3 & $25(19.5)$ & $27(27.5)$ \\
\hline ASA 4 & $12(9.4)$ & $7(7.2)$ \\
\hline Covid-19 swab molecular test results, $\mathrm{n}(\%)$ & & \\
\hline Negative & n.a. & $81(74.3)$ \\
\hline Positive & n.a. & $5(4.6)$ \\
\hline Not available & n.a. & $23(21.1)$ \\
\hline Legend: q1 = first quartile; q3 = third quartile; SD = standard deviation. \\
\hline
\end{tabular}

In terms of diagnoses, different percentages between Group 1 and Group 2 were registered for bowel obstruction ( $8.8 \%$ vs $18.3 \%$ ), acute appendicitis (11.7\% vs $19.4 \%)$, acute cholecystitis ( $5.8 \%$ vs $1.8 \%$ ), urinary tract obstruction ( $28.5 \%$ vs $21.1 \%)$, extra-uterine pregnancy $(2.2 \%$ vs $6.4 \%)$ and pelvic inflammatory disease (PID) (2.2\% vs $4.6 \%)$ (Table 1$)$.

In Group 2 in respect to Group 1, the total number of procedures categorized by a single clinical unit showed differences with decreased percentages for General Surgery 1 and Urology, and with increased percentages for General Surgery 2 and Gynecology $(p<0.01)$. (Table 3$)$. 
Table 3

Comparison of clinical management between Groups.

\begin{tabular}{|c|c|c|c|}
\hline \multirow[t]{4}{*}{ Characteristics } & Group 1 & Group 2 & \multirow[t]{4}{*}{ p-value } \\
\hline & 2019 & 2020 & \\
\hline & (137 Pts) & (109 Pts) & \\
\hline & $\mathrm{n}(\%)$ & $n(\%)$ & \\
\hline \multicolumn{4}{|l|}{ Surgical Units } \\
\hline General Surgery 1, n (\%) & $62(30.6)$ & $26(23.85)$ & \multirow[t]{4}{*}{$<0.01$} \\
\hline General Surgery 2, n (\%) & $20(14.6)$ & $31(28.4)$ & \\
\hline Ginecology, n (\%) & $23(16.8)$ & $26(23.85)$ & \\
\hline Urology, n (\%) & $52(38.0)$ & $26(23.85)$ & \\
\hline \multicolumn{4}{|l|}{ Surgical Approach } \\
\hline Laparoscopy, n (\%) & $49(35.8)$ & $37(33.9)$ & \multirow[t]{5}{*}{0.17} \\
\hline Open, n (\%) & $23(16.8)$ & $29(26.6)$ & \\
\hline Endoscopic, n (\%) & $49(35.8)$ & $26(23.8)$ & \\
\hline Vaginal, n (\%) & $5(3.6)$ & $5(4.6)$ & \\
\hline Others, n (\%) & $11(8.0)$ & $12(11.1)$ & \\
\hline ICU admissions, n (\%) & $9(6.9)$ & $3(3.1)$ & 0.24 \\
\hline
\end{tabular}


Table 4

A. Perioperative outcomes.

\begin{tabular}{|c|c|c|c|}
\hline \multirow[t]{3}{*}{ Characteristics } & Group 1 & Group 2 & \multirow[t]{3}{*}{ p-value } \\
\hline & 2019 (137 Pts) & 2020 (109 Pts) & \\
\hline & $n(\%)$ & $\mathrm{n}(\%)$ & \\
\hline Intra-operative complications, n (\%) & $0(0)$ & $1(1)$ & 0.43 \\
\hline Total DRG, median (q1-q3) & $1.0(0.8-1.9)$ & $1.1(0.6-1.9)$ & 0.93 \\
\hline Post-operative LOS, median (q1-q3) & $3(1-8)$ & $4(2-9)$ & 0.13 \\
\hline \multicolumn{4}{|l|}{ Discharge destination, $\mathrm{n}(\%)$} \\
\hline Home & $124(91.2)$ & $99(90.8)$ & \multirow[t]{4}{*}{0.85} \\
\hline Nursing home & $3(2.2)$ & $3(2.8)$ & \\
\hline Rehabilitation & $8(5.9)$ & $5(4.6)$ & \\
\hline Death/intrahospital mortality & $1(0.7)$ & $2(1.8)$ & \\
\hline
\end{tabular}


Table 4

B. Comparison of clinical outcome: numbers, percentages, crude and adjusted outcome measures for the two patients' groups

\begin{tabular}{|c|c|c|c|c|}
\hline Outcome & $\begin{array}{l}\text { Group } \\
1 \\
2019 \\
(137 \\
\text { Pts) } \\
n(\%)\end{array}$ & $\begin{array}{l}\text { Group } \\
2 \\
2020 \\
(109 \\
\text { Pts) } \\
n(\%)\end{array}$ & $\begin{array}{l}\text { Crude OR }(95 \% \mathrm{Cl}), \mathrm{p} \text { - } \\
\text { value }\end{array}$ & $\begin{array}{l}\text { Adjusted } O R^{*}(95 \% \mathrm{Cl}), \mathrm{p}- \\
\text { value }\end{array}$ \\
\hline Morbidity & $\begin{array}{l}15 \\
(11.5)\end{array}$ & $\begin{array}{l}22 \\
(22.4)\end{array}$ & $\begin{array}{l}\mathrm{OR}=2.22(1.08-4.55), \mathrm{p} \\
=0.03\end{array}$ & $\begin{array}{l}\mathrm{aOR}=2.28(1.04-5.03), \mathrm{p} \\
=0.04\end{array}$ \\
\hline Dindo Clavien 0-2 & $\begin{array}{l}121 \\
(93.1)\end{array}$ & $\begin{array}{l}87 \\
(88.8)\end{array}$ & & \\
\hline Dindo Clavien 3-4 & $8(6.1)$ & $9(9.2)$ & & \\
\hline Dindo- Clavien 5 & $1(0.8)$ & $2(2.0)$ & & \\
\hline Blood transfusion & $\begin{array}{l}17 \\
(13.1)\end{array}$ & $8(8.2)$ & $\begin{array}{l}\mathrm{OR}=0.59(0.24-1.43), \mathrm{p} \\
=0.24\end{array}$ & $\begin{array}{l}\mathrm{aOR}=0.52(0.19-1.40), \mathrm{p} \\
=0.20\end{array}$ \\
\hline $\begin{array}{l}\text { Death/intrahospital } \\
\text { mortality }\end{array}$ & $1(0.7)$ & $2(1.8)$ & $\begin{array}{l}\mathrm{OR}=2.52(0.23-28.20) \\
\mathrm{p}=0.45\end{array}$ & $\begin{array}{l}\mathrm{aOR}=4.38(0.19-99.78) \\
\mathrm{p}=0.35\end{array}$ \\
\hline 30-days mortality & $4(3.1)$ & $4(4.1)$ & $\begin{array}{l}\mathrm{OR}=1.34(0.33-5.50), \mathrm{p} \\
=0.68\end{array}$ & $\begin{array}{l}\mathrm{aOR}=1.65(0.33-8.29), \mathrm{p} \\
=0.54\end{array}$ \\
\hline
\end{tabular}

\section{Clinical outcomes}

Intra-operative complications, LOS, and discharge destination showed no differences between the two Groups. In Group 2 versus Group 1, the overall morbidity increased significantly (more than doubled, OR = $2.22,95 \% \mathrm{Cl}=1.08-4.55, \mathrm{p}=0.03)$. The risk of blood transfusion decreased by $41 \%(\mathrm{OR}=0.59,95 \% \mathrm{Cl}=$ $0.24-1.43, p=0.24)$, and the 30 -day mortality increased by $34 \%(O R=1.34,95 \% \mathrm{Cl}=0.33-5.50, p=0.68)$, although the intergroup differences for the two last variables were not statistically significant. The adjusted analysis for ASA score, age, $\mathrm{CCl}$, and NEWS confirmed the outcomes found in the first crude analysis. Postoperative morbidity risk increased in Group 2 versus Group $1(\mathrm{aOR}=2.28,95 \% \mathrm{Cl}=1.04-$ $5.03, p=0.04$ ) but blood transfusion rate and 30 -day mortality risk were similar in the two Groups. Perioperative outcomes are displayed in Tables 4A and 4B. 


\section{Subgroup analyses of Group 2 subjects}

A crude analysis of the delayed access cohort showed a three times increased post-operative complications risk $(\mathrm{OR}=3.19,95 \% \mathrm{Cl}=0.89-11.44, \mathrm{p}=0.07)$. The blood transfusion risk increased by five times $(\mathrm{OR}=5.13,95 \% \mathrm{Cl}=1.05-25.15, \mathrm{p}=0.04)$, the 30-day mortality risk increased by eight times $(\mathrm{OR}=$ $8.00,95 \% \mathrm{Cl}=1.01-63.23, \mathrm{p}=0.05)$ and stoma risk for surgery units patients increased by $59 \%(\mathrm{OR}=1.59$, $95 \% \mathrm{Cl}=0.15-17.1, \mathrm{p}=0.70)$ for the delayed access group vs no delayed access complaints (Table 5). The adjusted analyses lowered the magnitude of the differences and canceled the statistical significance (Table 5).

Table 5

Clinical outcomes analysis of Group 2.

\begin{tabular}{|c|c|c|c|c|c|}
\hline & $\begin{array}{l}\text { No declared } \\
\text { delayed } \\
\text { access } \\
\mathrm{n}=87(84.5 \%)\end{array}$ & $\begin{array}{l}\begin{array}{l}\text { Declared } \\
\text { delayed } \\
\text { access }\end{array} \\
\mathrm{n}=16 \\
(15.5 \%)\end{array}$ & $\begin{array}{l}\text { p- } \\
\text { value }\end{array}$ & $\begin{array}{l}\text { Crude OR } \\
(95 \% \mathrm{Cl}), \\
\text { p-value }\end{array}$ & $\begin{array}{l}\text { Adjusted OR* } \\
(95 \% \mathrm{Cl}), \\
\text { p-value }\end{array}$ \\
\hline $\begin{array}{l}\text { Intra-operative } \\
\text { complications, n } \\
(\%)\end{array}$ & $0(0.0)$ & $1(8.3)$ & 0.13 & & \\
\hline Morbidity, n (\%) & $15(18.3)$ & $5(41.7)$ & & $\begin{array}{l}\mathrm{OR}=3.19 \\
(0.89-11.44) p \\
=0.07\end{array}$ & $\begin{array}{l}\text { aOR }=2.31 \\
(0.51-10.45) p \\
=0.28\end{array}$ \\
\hline $\begin{array}{l}\text { Dindo Clavien 0-2, } \\
\text { n (\%) }\end{array}$ & $73(89.0)$ & $10(83.3)$ & 0.01 & n.a. & n.a. \\
\hline $\begin{array}{l}\text { Dindo Clavien 3-4, } \\
\text { n (\%) }\end{array}$ & $9(11.0)$ & $0(0.0)$ & & & \\
\hline $\begin{array}{l}\text { Dindo- Clavien 5, n } \\
(\%)\end{array}$ & $0(0.0)$ & $2(16.7)$ & & & \\
\hline $\begin{array}{l}\text { Blood } \\
\text { transfusions, n (\%) }\end{array}$ & $5(6.10)$ & $3(25.0)$ & & $\begin{array}{l}\mathrm{OR}=5.13 \\
(1.05-25.15) \mathbf{p} \\
=\mathbf{0} .04\end{array}$ & $\begin{array}{l}\mathrm{aOR}=3.70 \\
(0.63-21.60) \mathrm{p} \\
=0.15\end{array}$ \\
\hline $\begin{array}{l}\text { 30-days mortality, } \\
\text { n (\%) }\end{array}$ & $2(2.4)$ & $2(16.7)$ & & $\begin{array}{l}\mathrm{OR}=8.00 \\
(1.01-63.23) \mathbf{p} \\
=\mathbf{0} .05\end{array}$ & $\begin{array}{l}\mathrm{aOR}=3.65 \\
(0.24-54.69) \mathrm{p} \\
=0.35\end{array}$ \\
\hline Stoma** & $3(6.5)$ & $1(10.0)$ & & $\begin{array}{l}1.59(0.15- \\
17.1) p=0.70\end{array}$ & $\begin{array}{l}\text { aOR }=1.11 \\
(0.07-18.52) p \\
=0.94\end{array}$ \\
\hline \multicolumn{6}{|c|}{ Legend: $\mathrm{aOR}=$ adjusted Odds Ratio; $\mathrm{Cl}=$ Confidence Interval; $\mathrm{OR}=$ Odds Ratio } \\
\hline \multicolumn{6}{|c|}{ *=adjusted for ASA score, age, CCI and NEWS } \\
\hline$\star *=$ only for operatio & performed in & aral Sur & & & \\
\hline
\end{tabular}


Positive SARS-CoV-2 patients had higher risk of blood transfusion ( $20 \%$ vs $7.8 \%, p=0.37)$, ICU admissions ( $20 \%$ vs $2.6 \%, p=0.17$ ) and median LOS ( 9 days vs 4 days, $p=0.11$ ), although differences did not reach statistical significance. Tables 6 and 7 show the impact of SARS-CoV-2 positivity on two subGroup 2 (SARS-Cov-2 negative versus SARS-Cov-2 positive).

Table 6

Impact of SARS-Cov-2 positivity on outcomes on Group 2

\begin{tabular}{|c|c|c|c|c|}
\hline Outcome & $\begin{array}{l}\text { SARS-Cov-2 } \\
\text { negative } \\
\mathrm{N}=81(94.2)\end{array}$ & $\begin{array}{l}\text { SARS-Cov-2 } \\
\text { positive } \\
\mathrm{N}=5(5.8)\end{array}$ & $\begin{array}{l}\text { p- } \\
\text { value }\end{array}$ & $\begin{array}{l}\text { Crude OR }(95 \% \mathrm{Cl}), \mathrm{p} \text { - } \\
\text { value }\end{array}$ \\
\hline $\begin{array}{l}\text { Intra-operative } \\
\text { complications, n (\%) }\end{array}$ & $0(0.0)$ & $1(20.0)$ & 0.06 & n.a. \\
\hline $\begin{array}{l}\text { Post-operative morbidity, n } \\
(\%)\end{array}$ & $19(24.7)$ & $0(0.0)$ & 0.58 & n.a. \\
\hline Dindo Clavien 0-2, n (\%) & $67(87.0)$ & $5(100.0)$ & \multirow[t]{3}{*}{1.0} & \multirow[t]{3}{*}{ n.a. } \\
\hline Dindo Clavien 3-4, n (\%) & $8(10.4)$ & $0(0.0)$ & & \\
\hline Dindo Clavien 5, n (\%) & $2(2.6)$ & $0(0.0)$ & & \\
\hline Blood transfusions, n (\%) & $6(7.8)$ & $1(20.0)$ & 0.37 & $\begin{array}{l}2.96(0.28-30.85), p \\
=0.37\end{array}$ \\
\hline 30-days mortality, n (\%) & $3(3.9)$ & $0(0.0)$ & 1.0 & n.a. \\
\hline ICU admissions, n (\%) & $2(2.6)$ & $1(20.0)$ & 0.17 & $\begin{array}{l}9.37(0.69-126.56), p \\
=0.09\end{array}$ \\
\hline $\begin{array}{l}\text { Declared Delayed access > } \\
48 \mathrm{~h}, \mathrm{n}(\%)\end{array}$ & $9(11.8)$ & $1(20.0)$ & 0.49 & $\begin{array}{l}1.29(0.13-12.48), p \\
=0.82\end{array}$ \\
\hline $\begin{array}{l}\text { Post-operative LOS, median } \\
\text { (q1-q3) }\end{array}$ & $4(2-9)$ & $9(8-10)$ & 0.11 & n.a. \\
\hline $\begin{array}{l}\text { Legend: } \mathrm{Cl}=\text { confidence inter } \\
\text { first quartile; } \mathrm{q} 3=\text { third quarti }\end{array}$ & $\mathrm{CU}=$ Intensi & Unit; LOS = & f sta & $\mathrm{OR}=$ Odds Ratio; q1 = \\
\hline
\end{tabular}

\section{Discussion}

Covid 19 is a global pandemic disease that have forced major changes in human healthcare systems all around the world. In Italy, the exponential increase in severe cases led to a rise in hospitalizations with a progressive overcrowding in ICUs. As a consequence, we witnessed a switch from permanent emergency room's respirator stations to beds equipped with mechanical ventilation. This reorganization resulted in a greater demand for dedicated ICU personnel and a rapid decrease in planned surgeries.

During the lockdown period, EDs experienced a large influx of patients with respiratory failure due to COVID 19 related pneumonia and a rapid increase in cases requiring immediate treatment in parallel with 
the growing outbreak. A restructuration of all medical services was provided and in particular for patients in need of surgical care. Elective non-oncological surgery was temporarily allocated to a stand-by position mainly to relocate staff members, particularly anesthesiologists, to help with emergency cases and to switch the operative theatres into emergency rooms for the sickest COVID-19 patients. Non-operative management (NOM) of surgical patients had to be considered whenever possible. Only emergency cases and selected oncological procedures continued taking place.

In our region the public healthcare system closed five peripheral EDs to concentrate emergency surgical activity in our hub hospital only. Dedicated COVID 19 protocols was established. All surgical patients we screened for Covid-19 before admission to EDs. To prevent contamination of holding areas no patients were moved between different hospital areas until their destination had been confirmed ready and a dedicated COVID-19 operating theatre was designated.

To our knowledge this is one of the first studies analyzing the impact of COVID 19 disease and lockdown on emergency surgical procedures in a single hub hospital by comparing two cohorts of patients enrolled in the same time periods before and during the pandemic (2019 versus 2020). A unique feature of our study is the comparison of outcomes in the same clinical units having the same senior surgical staff before and during the pandemic. Our findings demonstrate the consequences of reduced ED resources for ordinary non-COVID-19 patients in need of emergency surgery during the pandemic.

We observed a decrease in overall emergency surgical activities of $20.4 \%(p=0.03)$ during the pandemic which is comparable to other international findings $(12,13)$. Nevertheless, bowel obstruction, acute appendicitis, extra-uterine pregnancy and pelvic inflammatory disease (PID) increased. Other authors have also found a change in clinical presentation of emergency cases during the COVID-19 pandemic with a reduction in less severe conditions like urinary tract pathology and an increase in some surgical conditions such as bowel obstruction, acute appendicitis, extra-uterine pregnancy and PID (14). These observations most likely have a multifactorial explanation. The Italian Government said that the most important action to save lives was for people to stay at home as much as possible. This restriction might explain the reduction of patients with hospital access due to "non-essential" surgical consults and trauma. Many people may have avoided visiting hospitals in fear of contracting COVID 19. General practitioners probably managed symptoms of abdominal pain, pelvic pain and urinary burning in patients' homes in a larger extent than before the pandemic. Lifestyle changes during lockdown may explain the lower incidence of some diseases like acute cholecystitis. The lower rate of cholecystectomy during the pandemic might be due to NOM using percutaneous cholecystostomy in more cases. Another aspect could be that surgeons adopted a more conservative behavior driven by fear of becoming patients themselves (15). Estimates show that $85 \%$ of healthcare workers get exposed to the virus and the International Council of Nurses estimated an infection rate of $9 \%$ in Italy during period March-April 2020 (16). Finally, as many elective procedures were postponed, fewer patients required emergency surgical revision due to complications. Interestingly, patients undergoing surgery were similar before and during the pandemic regarding gender, age, frailty and comorbidity, as assessed by NEWS and $\mathrm{CCl}$ (17). The Italian World Bank Staff estimates that Italy has the second largest proportion of older adults in the world 
(18). Therefore, Italian EDs are used to manage older subjects who are more susceptible to and more strongly affected by COVID-19 with at greater risk of developing emergency surgical conditions and related complications. In this study patients' median age was only slightly lower during the pandemic but we didn't observe any statistically significant differences regarding the age.

A declared delayed access to ED of 48-92 hours from the onset of clinical signs was observed in $15.5 \%$ of patients during the pandemic. Several factors could explain this finding such as changes in outpatient pathways (19) and patients' fear of going to hospitals and becoming infected with COVID-19 (20). Many surgical patients were initially treated without surgery. Acute appendicitis, acute cholecystitis, uncomplicated diverticulitis and urinary tract infections were given antibiotics only. Hence, many subjects were not referred to hospital until after NOM failure and in a worse clinical condition. Cano-Valderrama et al (21) observed a decrease of $65.4 \%$ in emergency surgical activity in a Spanish hospital caused by delayed access. They also found an increased proportion of emergency surgery cases without alternative treatments, such as intestinal obstruction and incarcerated hernia. Consequently, patients requiring surgical care presented with more advanced disease due to delayed admission. This explains the poorer patient outcomes in the declared delayed access cohort in our Group 2. On logistic regression analysis, a delayed access predicted an increase in postoperative morbidity, blood transfusion and 30-days mortality rate.

An open surgical approach was used more often during the pandemic. This was conditioned by the clinical status of patients but we did not find any significant difference in terms of mortality or morbidity as compared with 2019-data. However, patients in the open surgery group had an increased blood transfusion crude rate, which was probably due to a higher numbers of patients presenting with active bleeding, obstruction, perforation or need of a rapid damage control. Institutions like Centers for Disease Control and Prevention in US and the American College of Surgeons (22) recommend using negativepressure operative rooms for patients who are positive or suspected of having COVID-19 infection. Authors of research papers (23) support this recommendation. The rationale is that pneumoperitoneum leakage may cause aerosol exposure for the operating team during standard laparoscopy (24). Active replication of the SARS-CoV-2 virus occurs in the respiratory and gastrointestinal tracts (25) and De Simone et al (26) suggested that laparoscopy on COVID-19 patients should better be avoided, especially in an emergency setting. The United Kingdom Royal College of Surgeons suggested considering miniinvasive surgery in highly selected individual cases only where clinical benefits to patients substantially exceed the risk of potential viral transmission (27). Zheng et al. advised caution with laparoscopy, limiting the intra-abdominal pressure, reducing the electrocautery settings and minimizing the Trendelenburg position (28). A switch of surgical approach from minimally-invasive to open was observed especially for procedures in general surgery or in case of emergency bowel disease in order to avoid intestinal virus spreading. However, up to date there is low evidence for an increased risk of contamination of health care providers during laparoscopy, nor of operating room pressure, surgical smoke, tissue extraction or $\mathrm{CO}_{2}$ deflation (29). Therefore, abandoning laparoscopic surgery in favor of open surgery for fear of COVID-19 infection among staff is actually not justified. While median LOS was 
not statistically different in the two groups, detailed analysis showed an increase in median LOS during the pandemic. Delayed access and increased morbidity justified a longer length of stay.

Morbidity rate increased during the pandemic, especially Dindo Clavien score $>3$. Subjects with older age, frailty, sepsis, delayed hospital access, comorbities and those who were admitted during lockdown were at higher risk of complications. According to Mc Lean et al (14) patients in need of emergency surgery should attend promptly and receive the surgical care that they require immediately. The risk of perioperative complications associated with COVID 19 disease is significant and can affect morbidity and mortality (30). The COVID Surg Collaborative group performed an international multicenter cohort study on patients undergoing surgery. In adjusted analyses of the COVID 19 positive test group, 30-day mortality and morbidity (Dindo Clavien $>3$ ) were associated with age $>70$ years, ASA score $>3$ and emergency surgery versus elective surgery (OR 1.67 [1.06-2.63], $p=0.026)(31)$. The low number of COVID-19 patients in our series does not allow any conclusions in this respect.

\section{Study Limitations}

The retrospective and observational nature of our study could affect the general strength of the results. Due to the retrospective design, potentially useful data might have escaped collection and thus might have limited in depth analyses. On the other hand, the historical period of the first wave of the COVID-19 pandemic has to be analyzed based on data from the real-world scenario.

Moreover, for subgroup analyses the small sample size and small number of events did not allow us to draw solid conclusions. Some diagnoses and baseline characteristics were not homogeneous between groups, thus limiting the robustness of the results. However, a detailed description of the observed differences still provides data of clinical relevance. Indeed, the Covid-19 pandemic is a global healthcare emergency that generates a cascade of important health problems which deserves further analysis and comments.

\section{Conclusions}

Our tertiary referral teaching regional hospital experienced a decrease in surgical emergency admissions and operations during the COVID-19 pandemic and lockdown period in the spring of 2020. SARS-CoV-2 infection was diagnosed preoperatively in $5 / 86$ of operated patients $(5.8 \%)$. As compared with the same time period in 2019 there was an increase in the use of ambulance for pre-hospital transfer of patients. A declared delay in access to hospital was registered significantly more often during the pandemic $(15.5 \%$, $p<0.01)$. Our findings show that COVID-19 affected surgical care with higher morbidity rates due to more low-grade complications. The overall morbidity and 30-day mortality increased significantly. Delayed access was closely related with increased morbidity, blood transfusion and the 30-day mortality risk. Positive SARS-CoV-2 patients had higher risk of blood transfusion, ICU admissions and median LOS. 
We believe delayed ED access is due a "filter effect" induced by the COVID-fear in the population. As a result, only the most severe cases were referred to the emergency department. Further research is needed to corroborate our assumption that the COVID-19 pandemic changed the emergency surgery management and its results. Further analysis of pooled data could allow the international community to better identify patients that should be referred promptly to emergency departments and which patients that may benefit from non-operative management.

\section{Abbreviations}

WHO

World Health Organization

ED

Emergency Department

NRS

Numeric Rating Scale

NEWS

National Early Warning Score

$\mathrm{CCl}$

Charlson Comorbidity index score

ASA

American Society of Anesthesiologists

ICU

Intensive Care Unit

DRG

Diagnosis Related Groups

LOS

length of hospital stay

NOM

Non-operative management

PID

pelvic inflammatory disease

\section{Declarations}

Ethics approval : All procedures performed in studies involving human participants were in accordance with the ethical standards of the institutional and/or national research committee and with the 1964 Helsinki declaration and its later amendments or comparable ethical standards. Study-specific approval by the appropriate local ethics (Azienda Provinciale per i Servizi Sanitari-Trento, Italy) on committee for research.

Consent to participate : For this type of study formal consent is not require 
Consent for publication: not available

Availability of data and material: The datasets generated during and/or analysed during the current study are available from the corresponding author on reasonable request.

Conflicts of interest/Competing interests : The authors declare that they have no competing interests. All authors certify that they have no affiliations with or involvement in any organization or entity with any financial interest or non-financial interest in the subject matter or materials discussed in this manuscript.

Funding: The authors did not receive support from any organization for the submitted work.

\section{AUTHORS' CONTRIBUTIONS}

Conceptualization, Methodology, Formal analysis and investigation: AC, TC, FAC, LM.

Ethical Committee relationship: LM

Statistical analysis and interpretation of data for the work: MR, GN, FAC.

Writing - original draft preparation: FAC

Writing - review and editing: AC, TC, FAC, LM, MR, ST, GM, GT, PB, AF, GMG, MG, GN, AB.

Final approval of the version to be published: $A C, T C, F A C, L M$ and $A B$.

English Language Editing: TEBJ

Supervision: $A B$ and TEBJ

\section{ACKNOWLEDGEMENTS}

Not applicable

\section{References}

1. Li Q, Guan X, Wu P, et al. Early Transmission Dynamics in Wuhan, China, of Novel CoronavirusInfected Pneumonia. N Engl J Med. 2020;26:382:1199-207. https://doi. 10.1056/NEJMoa2001316.

2. World Health Organization. Director-General's opening remarks at the media briefing on COVID-1911 March 2020. https://www.who.int/dg/speeches/detail/who-director-general-s-opening-remarks-atthe-media-briefing-on-covid-19--11-march-2020. Accessed 3 November 2020.

3. The COVID-19 Task force of the Department of Infectious Diseases and the Italian Service. - Istituto Superiore di Sanità.

https://www.epicentro.iss.it/coronavirus/bollettino/Infografica_1maggio\%20ITA.pdf. Accessed 3 November 2020. 
4. Di Saverio S, Pata F, Gallo G, et al (2020) Coronavirus pandemic and colorectal surgery: pratical advice based on Italian experience. Colorect Dis https: //doi.org/10.1111/codi.15056.

5. von Elm E, Altman DG, Egger M, et al. STROBE Initiative. Strengthening the Reporting of Observational Studies in Epidemiology (STROBE) statement: guidelines for reporting observational studies. BMJ. 2007;20:335:806-8. https://doi. 10.1136/bmj.39335.541782.

6. Thong ISK, Jensen MP, Miró J, Tan G. The validity of pain intensity measures: what do the NRS, VAS, VRS, and FPS-R measure? Scand J Pain. 2018;26:18:99-107. https://doi. 10.1515/sjpain-20180012.

7. Royal College of Physicians. National Early Warning Score (NEWS). Standardising the assessment of acute-illness severity in the NHS. Report of a working party. London: RCP; 2012.

8. Charlson ME, Pompei P, Ales KL, MacKenzie CR. A new method of classifying prognostic comorbidity in longitudinal studies: development and validation. J Chronic Dis. 1987;40:373-83. https://doi. 10.1016/0021-9681(87)90171-8.

9. Freund Y, Lemachatti N, Krastinova E, Van Laer M, Claessens YE, Avondo A, Occelli C, Feral-Pierssens AL, Truchot J, Ortega M, Carneiro B, Pernet J, Claret PG, Dami F, Bloom B, Riou B, Beaune S, French Society of Emergency Medicine Collaborators Group. Prognostic Accuracy of Sepsis-3 Criteria for InHospital Mortality Among Patients With Suspected Infection Presenting to the Emergency Department. JAMA. 2017;317:301-8. htpps://doi. 10.1001/jama.2016.20329.

10. Clavien PA, Barkun J, de Oliveira ML, Vauthey JN, Dindo D, Schulick RD, de Santibañes E, Pekolj J, Slankamenac K, Bassi C, Graf R, Vonlanthen R, Padbury R, Cameron JL, Makuuchi M. (2009) The Clavien-Dindo classification of surgical complications: five-year experience. Ann Surg 250:187 - 96. Htpps://doi: 10.1097/SLA.0b013e3181b13ca2.

11. Nonis M, Bertinato L, Arcangeli L, Cadeddu C, Palinuro A, Frattura L, Merlino GL, Verdini E, Lispi L, Ricciardi W. The evolution of DRG system in Italy: the It-DRG project. Eur J Pub Health. 2018. https://doi.org/10.1093/eurpub/cky218.095.

12. Thornton J. Covid-19: A\&E visits in England fall by 25\% in week after lockdown. BMJ https://. 2020. doi:10.1136/bmj.m1401.

13. Porreca A, Colicchia M, D'Agostino D. Urology in the Time of Coronavirus: Reduced Access to Urgent and Emergent Urological Care during the Coronavirus Disease 2019 Outbreak in Italy. Urol Int. 2020;104:631-6. https://doi. 10.1159/000508512.

14. McLean RC, Young J, Musbahi A, Et al. A single-centre observational cohort study to evaluate volume and severity of emergency general surgery admissions during the COVID-19 pandemic: is there a "lockdown" effect? Int J Surg https://. 2020. doi:10.1016/j.jjsu.2020.09.011.

15. Ng K, Poon BH, Kiat Puar TH, et al. COVID-19 and the Risk to Health Care Workers: A Case Report. Ann Intern Med. 2020;2:172:766-7. https://doi. 10.7326/L20-0175.

16. International Council of Nurses. ICN tells BBC World News viewers. Rising rate in CO- VID-19 infection amongst health workers re- quires urgent action. . Accessed 3 November 2020. 
17. Spagnolli W, Rigoni M, Torri E, Cozzio S, Vettorato E, Nollo G. Application of the National Early Warning Score (NEWS) as a stratification tool on admission in an Italian acute medical ward: A perspective study. Int J Clin Pract https://. 2017. doi:10.1111/ijcp.12934.

18. World Bank. Population ages 65 and above (\% of total population). World Dev Indic 2019. https://data.worldbank.org/indicator/SP.POP.65UP.TO. Accessed 3 November 2020.

19. Kelly ME, Murphy E, Bolger JC, Cahill RA. COVID-19 and the treatment of acute appendicitis in Ireland: a new era or short-term pivot? Colorectal Dis. 2020;22:648-9. https://doi. 10.1111/codi.15141.

20. Mantica G, Riccardi N, Terrone C, Gratarola A. (2020) Non-COVID-19 visits to emergency departments during the pandemic: the impact of fear. Public Health 183:40-1. https://doi:

10.1016/j.puhe.2020.04.046.

21. Cano-Valderrama $\mathrm{O}$, Morales $\mathrm{X}$, Ferrigni $\mathrm{CJ}$, et al. Reduction in emergency surgery activity during COVID-19 pandemic in three Spanish hospitals. Br J Surg https://. 2020. doi:10.1002/bjs.11667.

22. Interim Guidance for Healthcare Facilities. Preparing for Community Transmission of COVID-19 in the United States Available at: https://www.cdc.gov/coronavirus/2019-ncov/healthcarefacilities/guidance-hcf.html March 15 2020.,https://www.facs.org/covid-19/clinical-guidance. Accessed 3 November 2020.

23. Ti LK, Ang LS, Foong TW, Ng BSW. What we do when a COVID-19 patient needs an operation: operating room preparation and guidance. Can J Anaesth. 2020;67:756-8.

24. $\mathrm{Li} \mathrm{Cl}$, Pai JY, Chen $\mathrm{CH}$. Characterization of smoke generated during the use of surgical knife in laparotomy surgeries. J Air Waste Manag Assoc. 2020;70:324-32. https://doi. 10.1080/10962247.2020.1717675.

25. Xiao F, Tang M, Zheng X, Liu Y, Li X, Shan H. (2020) Evidence for Gastrointestinal Infection of SARSCoV-2. Gastroenterology 158:1831-3.e3. https://doi: 10.1053/j.gastro.2020.02.055.

26. De Simone B, Chouillard E, Di Saverio S, et al. Emergency surgery during the COVID-19 pandemic: what you need to know for practice. Ann R Coll Surg Engl. 2020;102:323-32. https://doi. 10.1308/rcsann.2020.0097.

27. Royal College of Surgeon of England. Updates intercollegiate general surgical guidance on COVID 19. https://www.rcseng.ac.uk/coronavirus/joimt-guidance-for-surgeons-v2. Accessed 3 November 2020.

28. Zheng MH, Boni L, Fingerhut A. Minimally Invasive Surgery and the Novel Coronavirus Outbreak: Lessons Learned in China and Italy. Ann Surg https:// . 2020. doi:10.1097/SLA.0000000000003924.

29. de Leeuw RA, Burger NB, Ceccaroni M, et al. COVID-19 and Laparoscopic Surgery: Scoping Review of Current Literature and Local Expertise. JMIR Public Health Surveill https://. 2020. doi:10.2196/18928.

30. Babidge WJ, Tivey DR, Kovoor JG. Surgery triage during the COVID-19 pandemic. ANZ J Surg. 2020;90:1558-65. https://doi. 10.1111/ans.16196. 
31. COVIDSurg C. Mortality and pulmonary complications in patients undergoing surgery with perioperative SARS-CoV-2 infection: an international cohort study. Lancet. 2020;4:396:27-38. https://doi. 10.1016/S0140-6736(20)31182-X. 